\title{
Environmental Enrichment Intervention in Animal Models of Autism
}

\author{
Ying Xiao1*
}

${ }^{1}$ Dermatology Branch, Center of Cancer Research, National Cancer Institute, National Institutes of Health, Bethesda, MD 20892, USA.

*Correspondence: Ying Xiao, Email: xy9908@gmail.com.

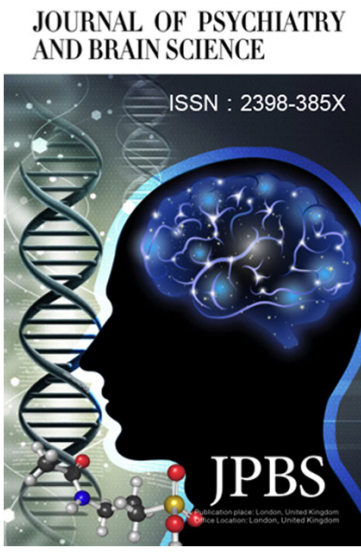

http://jpbs.qingres.com

\section{fOPEN ACCESS}

DOI: 10.20900/jpbs.20170018

Received: November 11, 2017

Accepted: November 11, 2017

Published: December 25, 2017

Copyright: $\odot 2017$ Cain et al. This is an open access article distributed under the terms of the Creative Commons Attribution License, which permits unrestricted use, distribution, and reproduction in any medium, provided the original author and source are credited.

\begin{abstract}
Autism spectrum disorder (ASD) is a complex neurodevelopment disorder caused by genetic and environmental factors. Animal models of autism could help to explore the cellular and molecular mechanisms underlying the pathogenesis and treatment approaches of this disease. Environmental enrichment has been demonstrated to exert beneficial effects in wild-type rodents as well as animal models of various neurological and psychiatric disorders. Here we review the findings about the effect of environmental enrichment on animal models of autism. Generally, environmental enrichment results in less anxietylike behavior, reduces repetitive behavior and the deficits in social and cognitive behaviors. Environmental enrichment therefore appears to be an effective model for non-pharmacological intervention in autism therapy.
\end{abstract}

Key words: Autism; Animal model; Behavior; Environmental enrichment

\section{INTRODUCTION OF AUTISM}

Autism spectrum disorder (ASD) is a complex neurodevelopment disorder, characterized by core features of impairments in social interaction and communication, and repetitive and stereotyped behaviors ${ }^{[1]}$, along with some co-occurring symptoms such as sleeping disorder, anxiety and aggression ${ }^{[2]}$. The exact etiology of autism remains unclear. Numerous studies on twins and siblings found a more than $90 \%$ concordance rates in monozygotic twins ${ }^{[3,4]}$, as compared with $0-10 \%$ in dizygotic twins ${ }^{[3,4]}$ and $3-14 \%$ in siblings ${ }^{[5-7]}$, which revealed the contribution of genetic factors to this disorder. 
Using genetic techniques such as linkage studies, association studies and chromosomal studies, many genetic variations linked to autism have been identified, including several replicated susceptibility loci, maternal 15q11-13 duplications and mutations in the synaptic genes such as NRXN1, NLGN3, NLGN4 and SHANK3 ${ }^{[8]}$. Some human syndromes resulted from genetic alteration also display autistic symptoms, such as Rett syndrome (a mutation in MECP2) and Fragile $X$ syndrome (CGG repeats) ${ }^{[9,10]}$. Besides genetic factors, several environmental factors might also contribute to the development of autism, including prenatal viral infection, zinc deficiency, prenatal and perinatal stress, prenatal exposure to toxins such as valproic acid (VPA) and thalidomide ${ }^{[11]}$.

Currently there is no effective pharmacological therapy for the core symptoms of impairments in social interaction and communication in autism. Despite the many potential therapy targets suggested by basic neuroscience researches, there are only two FDA-approved medicine for autism, risperidone and aripiprazole ${ }^{[12]}$. Both of them are aimed at treating irritability in autism, including tantrums, aggression and self-injury, but not the core features $^{[13]}$. On the other hand, early behavioral interventions are currently the only well-established and effective treatment for autistic children ${ }^{[14-16]}$. Usually provided through special programs, these interventions use principles and procedures from Applied Behavior Analysis to provide intensive skilloriented training sessions to help children to develop adaptive and functional skills.

Studies using structural and functional imaging techniques have revealed neurobiological abnormalities of the autistic brains ${ }^{[17]}$. Magnetic resonance imaging (MRI) scans found an abnormal overgrowth of the autistic brain during infancy and early childhood ${ }^{[18]}$. Magnetic resonance spectroscopic imaging revealed brain chemical abnormalities in autistic children aged at 3-4, showing a reduced concentrations of neuron-related molecules such as $\mathrm{N}$-acetylaspartate, creatine, and myoinositol ${ }^{[19]}$. Post mortem studies found decrease in Purkinje neurons and cerebral cortex dysgenesis in autistic brains ${ }^{[17]}$. However, although these noninvasive imaging techniques and post mortem studies could reveal some structural and functional abnormalities of autistic brains, it is difficult to use these techniques to investigate the detailed molecular pathogenesis of this disease ${ }^{[20]}$. On the other hand, experimental animal models, which allow invasive studies, provide opportunities to explore the detailed cellular and molecular mechanisms underlying the pathogenesis and treatment approaches of this disease ${ }^{[21]}$.
Several genetic and non-genetic rodent models have been developed to mimic human autistic symptoms. According to Nestler, et al, an effective animal model of neuropsychiatric disorder should meet three criteria of validity: face validity (which refers that the model resembles important features of the human disease), construct or etiologic validity (which refers that the model is constructed in a way that causes the disease in humans), and predictive validity (which refers that effective treatment in humans should also be effective on the animal models) ${ }^{[20]}$. Animal models of autism are commonly generated based on the etiology of autism, either by genetic manipulation to induce genetic variations that are observed in human autism patients, or by exposing the pregnant animals to certain chemicals that are known to induce autism in human ${ }^{[9]}$. Some inbred mouse strains expressing phenotypes relevant to autism are also used as autism models ${ }^{[22]}$.

Although it is helpful to employ animal models of autism to study the detailed mechanism underlying behavioral intervention therapy, it is difficult to model the behavioral therapies in animals. Environmental enrichment is a common nonpharmacological treatment used in animal models of developmental and degenerative disorders, and was approximately used as a model of human early behavioral intervention ${ }^{[23,24]}$. The following part of this review summarized the findings about the effect of environmental enrichment on some commonly used experimental autism models. We reviewed the approach of carrying out enriched environmental stimulation in autism models, the beneficial outcome and the neurobiological changes after intervention. Behavioral intervention is currently the only effective treatment of autism, and these studies in animal models may help better understanding the mechanism underlying the therapeutic processes.

\section{EFFECT OF ENVIRONMENT IN AUTISM MODELS}

Environmental enrichment refers to the addition of objects to the animals' environment which increases levels of novelty and complexity and enhances sensory stimulation, cognitive activity and physical exercise ${ }^{[25]}$. Various approaches are used to provide environmental enrichment to animals. One approach is to use physical enrichment by rearing animals in enriched cages, including lager space, equipments to climb and explore, toys of different color, shape and texture, and novelty (materials presented in cages are changed on schedule). Another approach is to use social enrichment, in which multiple animals 
are induced to facilitate social interaction.

In wild type rodents, environmental enrichment enhances learning and memory, reduces aging related memory decline, possibly through its effects on synaptic plasticity and hippocampal neurogenesis ${ }^{[26]}$. Environmental enrichment has also been demonstrated to exert beneficial effects in animal models of various neurological and psychiatric disorders, including Huntington's disease, Alzheimer's disease, Parkinson's disease, stroke, depression, etc. ${ }^{[26,27]}$. Here we summarized the current studies about the effect of environmental enrichment on animal models of autism.

\subsection{Effect of environmental enrichment on autism models generated by genetic manipulation}

\subsubsection{Fragile $X$ syndrome models}

Fragile $X$ syndrome is a common genetic disorder which causes mental retardation. It is caused by a CGG trinucleotide expansion (greater than 200 CGG repeats) in the fragile $X$ mental retardation 1 (Fmr1) gene on the $X$ chromosome which encodes the FMR protein. This genetic alteration results in the absence of the FMR protein, which controls synaptic plasticity and maturation ${ }^{[28]}$. Fragile $X$ syndrome shares some common symptoms as autism, including pragmatic deficits, language delays, reduced eye contact, difficulty with regulation of attention, selfinjury and aggression ${ }^{[29]}$. Fmrl knockout mice are the predominantly used animal model for Fragile $X$ syndrome. These mice also display several autisticlike features, including hyperactivity in the open field, perseveration and repetitive behaviors such as hand flapping and high level of self-grooming, and reduced affiliative behaviors toward a female ${ }^{[30]}$. Restivo, et al. found that Fmrl knockout mice showed impaired habituation, which was observed in autism ${ }^{[31,32]}$, and rearing in enriched cages could restore the habituation to objects in this mice model ${ }^{[33]}$. In this study enriched cages failed to reverse the hyperactivity in the open field ${ }^{[33]}$, while another study found that hyperactivity of this model was eliminated when animals were raised in social enriched environment ${ }^{[23]}$. Early social enrichment also rescued the reduced investigative / affiliative behaviors in male Fmrl knockout mice ${ }^{[23]}$. Postmortem studies discovered an reduction in the dendritic branching in the hippocampus of autistic children ${ }^{[34]}$. Fmrl knockout mice also showed a decrease of basal dendrite branching and this alternation was reversed by rearing in enriched cages ${ }^{[33]}$.

\subsubsection{Rett syndrome models}

Rett syndrome is an X-linked progressive disorder that affects in girls during early childhood. It is usually caused by mutations in MeCP2, a gene coding for methyl-CpG binding protein that regulates RNA splicing and chromatin remodeling ${ }^{[35]}$. Children with Rett syndrome exhibit autistic features in the early period of the disease. The autistic features include "lack of following and expressionless face", "lack of eye-to-eye contact", "hypersensitivity to sound", etc. [36]. MeCP2308/Y (generated by truncation at amino acid 308) and MeCP2Tg (overexpression of MeCP2) mice display increased anxiety-like behavior and stereotypies ${ }^{[37]}$. MECP-/y (MeCP2 null mutants) mice showed increased anxiety-like behavior in the open field and early environmental enrichment could rescue this behavior ${ }^{[38]}$. Enriched housing environment also rescued the increased anxietylike behavior in novelty suppressed feeding in the female heterozygous MeCP+/- mice ${ }^{[39]}$. BDNF is one of the transcriptional targets of MeCP2 and related with autism ${ }^{[40]}$. Serum BDNF levels were found to be significantly lower in females with typical autism, compared with controls ${ }^{[40]}$. In female MeCP+/mice, the protein levels of BDNF in hippocampus were significantly lower than that of wildtype mice while environmental enrichment normalized the hippocampal BDNF protein levels ${ }^{[39]}$. Similarly, environmental enrichment could augment cortical BDNF levels, which was decreased in MECP-/y mice [38]

\subsection{3 $\mu$-opioid receptor gene knockout mice}

Genetic variation in the $\mu$-opioid receptor gene (Oprm1) is reported to associate with social behaviors. Children carrying the Oprm1 A118G polymorphism display improved parent-child relations, and $\mathrm{G}$ allele carriers displayed significantly higher sensitivity to social rejection than $A$ allele homozygotes ${ }^{[41]}$. $\mu$-opioid receptor knockout mice display social deficits, including deficits in maternal separation induced ultrasonic vocalization and reduced maternal attachment in pups, and altered social reward in juvenile mice, and thus are proposed as a monogenic model of autism ${ }^{[41-}$ ${ }^{43]}$. Early social enrichment (double mothering) was reported to rescue the abnormal response to maternal separation in Oprm1 knockout pups, and restore the preference for a social stimulus versus an object as wildtype mice ${ }^{[44]}$.

\subsubsection{Potocki-Lupski syndrome model}


Potocki-Lupski syndrome is caused by a duplication of chromosome 17p11.2. Patients with this syndrome display abnormal behaviors such as anxiety, inattention, cognitive deficit and autistic symptom ${ }^{[45]}$. Mice models for Potocki-Lupski syndrome have been generated by chromosome engineering and these mice display all core autistic behaviors typically utilized to diagnose autism, including abnormal social interactions, impaired communication and the presence of restrictive or repetitive behavior, while rearing in enriched environment mitigated some of the abnormalities, resulted in less aggression and anxiety-like behavior ${ }^{[46]}$. Elevated serotonin was observed in about a third of patients with autism ${ }^{[4]}$. In this animal model, elevated serotonin was also observed, and enrichment was found to rescue the altered serotonin levels in the primary somatosensory cortex and decrease the levels of 5 -HIAA in the hippocampus ${ }^{[46]}$.

\subsection{Effect of environmental enrichment on inbred mouse models of autism}

Some inbred mouse strains expressing phenotypes relevant to autism are also used as autism models. Several studies revealed that C58/J mice displayed increased activity and repetitive behaviors, as well as less social approach in the three-chamber test ${ }^{[48-}$ ${ }^{511}$. Environmental enrichment (rearing in enriched cages) was reported to reduce repetitive behaviors and improve reversal learning in this strain ${ }^{[52,53]}$.

BTBR $T+t f / J$ is another inbred strain that serve as model of autism, which display avoidance of a nose-to-nose contact with conspecifics, reduced ultrasonic vocalization in social situations and high levels of repetitive self-grooming ${ }^{[54]}$. Social enrichment (peer-rearing with B6 mice) was reported to rescue sociability deficits, but not high level of repetitive self- grooming ${ }^{[5]}$, while rearing in enriched cages could reduce the time spent in repetitive grooming ${ }^{[56]}$.

\subsection{Effect of environmental enrichment on chemical induced autism models}

Prenatal exposure to VPA is commonly used to generate autism model in rodents. VPA is a frequently used antiepileptic drug. However, more and more evidence indicated a linkage between prenatal VPA exposure and an increase risk of autism ${ }^{[57]}$. To mimic human intra uterine exposure, animals were usually exposed during organogenesis, commonly between day 9 to $13^{[9]}$. Offsprings are reported to display autistic behaviors, including hyperactivity, repetitive and stereotypic behaviors, increased anxiety and decreased social behaviors ${ }^{[58]}$. In Wistar rats that were prenatally exposed to VPA, environmental enrichment (rearing in enriched cages) was reported to result in lower locomotor activity, less repetitive/stereotypic-like behavior, decreased anxiety-like behavior, increased number of social exploration and total social behaviors ${ }^{[59]}$. In ICR mice subjected to prenatal VPA exposure, environmental enrichment improved anxiety-like behavior, social deficits and cognitive impairment ${ }^{[60]}$. Prenatal VPA exposure also resulted in decreased dendritic spine density in the hippocampal CA1 region and this change could also be reversed by enriched housing ${ }^{[60]}$.

\section{CLINICAL APPLICATION OF ENVIRONMENTAL ENRICHMENT IN AUTISM}

Although environmental enrichment was used to model behavioral intervention in rodent models of autism, it is quite different from the early behavioral interventions that are used in autistic children. In clinical, environmental enrichment is rather a form of Sensory Enrichment Therapy ${ }^{\left[{ }^{[1]}\right.}$. Abnormal sensorybased behaviors are commonly observed in autism, displaying hyper or hypo-sensitivities in processing of auditory, visual or tactile sensory ${ }^{[62]}$. Thus it was suggested that this therapy might help to decrease abnormal sensory responses and ultimately result in reduction of other symptoms of autism ${ }^{[61]}$. Two randomized clinical trials were carried out by Woo, et al. to examine the effect of environmental enrichment in autistic children ${ }^{[63,64]}$. Compared with usual care, environmental enrichment resulted in significant decrease in autism symptoms, improved cognitive skills and receptive language skills, but did not affect expressing language skills. However, given the small sample sizes and short study durations, these results were considered to be of low strength of evidence for the effect of environmental enrichment in autism ${ }^{[65]}$. Thus further long-term follow-up and studies with larger sample sizes are still warranted.

\section{CONCLUSION}


In sum, although the effect of environmental enrichment on autism remains uncertain in clinical, it has been demonstrated to exert beneficial effects in several animal models of autism, resulting in less anxiety-like behavior, decreasing repetitive behavior and the reversing the deficits in social and cognitive behaviors. Environmental enrichment therefore provides an effective model for investigating the

\section{REFERENCES}

1. Association AP. Diagnostic and statistical manual of mental disorders (DSM-5®): American Psychiatric Pub; 2013.

2. Lai MC, Lombardo MV, Baron-Cohen S. Autism. Lancet. 2014 Mar 08; 383(9920): 896-910.

3. Bailey A, Le Couteur A, Gottesman I, Bolton P, Simonoff E, Yuzda E, et al. Autism as a strongly genetic disorder: evidence from a British twin study. Psychological medicine. 2009; 25(1): 6377.

4. Steffenburg S, Gillberg C, Hellgren L, Andersson L, Gillberg IC, Jakobsson G, et al. A Twin Study of Autism in Denmark, Finland, Iceland, Norway and Sweden. J Child Psychol Psyc. 1989 May; 30(3): 405-416.

5. Bolton P, Macdonald H, Pickles A, Rios P, Goode $\mathrm{S}$, Crowson $\mathrm{M}$, et al. A Case - Control Family History Study of Autism. J Child Psychol Psyc. 1994 Jul; 35(5): 877-900.

6. Constantino JN, Zhang Y, Frazier T, Abbacchi AM, Law P. Sibling Recurrence and the Genetic Epidemiology of Autism. Am J Psychiat. 2010 Nov; 167(11): 1349-1356.

7. Sumi S, Taniai H, Miyachi T, Tanemura M. Sibling risk of pervasive developmental disorder estimated by means of an epidemiologic survey in Nagoya, Japan. J Hum Genet. 2006 Jun; 51(6): 518-522.

8. Kumar RA, Christian SL. Genetics of autism spectrum disorders. Current Neurology and Neuroscience Reports. 2009 2009/05/01; 9(3): 188-197.

9. Ergaz Z, Weinstein-Fudim L, Ornoy A. Genetic and non-genetic animal models for autism spectrum disorders (ASD). Reproductive Toxicology. 2016; 64: 116-140.

10. Geschwind DH. Autism: Many Genes, Common Pathways? Cell. 2008; 135(3): 391-395. neurobiological changes after non-pharmacological intervention in autism therapy.

\section{CONFLICTS OF INTEREST}

The author declares that there is no conflict of interest regarding the publication of this paper.

11. Grabrucker AM. Environmental Factors in Autism. Frontiers in Psychiatry. 2012.

12. Sahin M, Sur M. Genes, Circuits, and Precision Therapies for Autism and Related Neurodevelopmental Disorders. Science (New York, NY). 2015; 350(6263): 10.1126/science. aab3897 aab.

13. Baribeau DA, Anagnostou E. An update on medication management of behavioral disorders in autism. Current psychiatry reports. 2014 Mar; 16(3): 437.

14. LeBlanc LA, Gillis JM. Behavioral interventions for children with autism spectrum disorders. Pediatric clinics of North America. 2012 Feb; 59(1): 147-164, xi-xii.

15. Dawson G, Burner K. Behavioral interventions in children and adolescents with autism spectrum disorder: a review of recent findings. Curr Opin Pediatr. 2011 Dec; 23(6): 616-620.

16. Kasari C. Update on behavioral interventions for autism and developmental disabilities. Current opinion in neurology. 2015 Apr; 28(2): 124-129.

17. DiCicco-Bloom E, Lord C, Zwaigenbaum L, Courchesne E, Dager SR, Schmitz C, et al. The Developmental Neurobiology of Autism Spectrum Disorder. The Journal of Neuroscience. 2006; 26(26): 6897.

18. Courchesne E, Campbell K, Solso S. Brain growth across the life span in autism: Agespecific changes in anatomical pathology. Brain Research. 2011 2011/03/22/; 1380(Supplement C): $138-145$.

19. Friedman SD, Shaw DW, Artru AA, Richards TL, Gardner J, Dawson G, et al. Regional brain chemical alterations in young children with autism spectrum disorder. Neurology. 2003 Jan 14; 60(1): 100-107.

20. Nestler EJ, Hyman SE. Animal models of 
neuropsychiatric disorders. Nat Neurosci. 2010 10//print; 13(10): 1161-1169.

21. Pignatelli M, Feligioni M, Piccinin S, Molinaro G, Nicoletti F, Nistico R. Synaptic plasticity as a therapeutic target in the treatment of autism-related single-gene disorders. Current pharmaceutical design. 2013; 19(36): 64806490.

22. Silverman JL, Yang M, Lord C, Crawley JN. Behavioural phenotyping assays for mouse models of autism. Nat Rev Neurosci. $2010 \mathrm{Jul}$; 11(7): 490-502.

23. Oddi D, Subashi E, Middei S, Bellocchio L, Lemaire-Mayo V, Guzman M, et al. Early social enrichment rescues adult behavioral and brain abnormalities in a mouse model of fragile $X$ syndrome. Neuropsychopharmacology : official publication of the American College of Neuropsychopharmacology. 2015 Mar 13; 40(5): 1113-1122.

24. Dawson G. Early behavioral intervention, brain plasticity, and the prevention of autism spectrum disorder. Development and psychopathology. 2008 Summer; 20(3): 775-803.

25. Hannan AJ. Review: Environmental enrichment and brain repair: harnessing the therapeutic effects of cognitive stimulation and physical activity to enhance experience-dependent plasticity. Neuropathology and Applied Neurobiology. 2014; 40(1): 13-25.

26. Nithianantharajah J, Hannan AJ. Enriched environments, experience-dependent plasticity and disorders of the nervous system. Nat Rev Neurosci. 2006 Sep; 7(9): 697-709.

27. Hannan AJ. Environmental enrichment and brain repair: harnessing the therapeutic effects of cognitive stimulation and physical activity to enhance experience-dependent plasticity. Neuropathol Appl Neurobiol. 2014 Feb; 40(1): 13-25.

28. Saldarriaga W, Tassone F, Gonzalez-Teshima LY, Forero-Forero JV, Ayala-Zapata S, Hagerman R. Fragile X syndrome. Colombia medica (Cali, Colombia). 2014 Oct-Dec; 45(4): 190-198.

29. Gross C, Hoffmann A, Bassell GJ, BerryKravis EM. Therapeutic Strategies in Fragile $X$ Syndrome: From Bench to Bedside and Back. Neurotherapeutics : the journal of the American Society for Experimental NeuroTherapeutics. $2015 \mathrm{Jul} ;$ 12(3): 584-608.

30. Kazdoba TM, Leach PT, Silverman JL, Crawley $\mathrm{JN}$. Modeling fragile $X$ syndrome in the Fmr1 knockout mouse. Intractable \& rare diseases research. 2014 Nov; 3(4): 118-133.

31. Cardinaux A, Nejati $H, K$ Rogers $C$, Tsourides K, Gandhi T, Kjelgaard M, et al. Decreased Habituation to Naturalistic Stimuli in Autism 2015.

32. Webb SJ, Jones EJH, Merkle K, Namkung J, Toth K, Greenson J, et al. TODDLERS WITH ELEVATED AUTISM SYMPTOMS SHOW SLOWED HABITUATION TO FACES. Child neuropsychology : a journal on normal and abnormal development in childhood and adolescence. 2010 03/18; 16(3): 255-278.

33. Restivo L, Ferrari F, Passino E, Sgobio C, Bock J, Oostra BA, et al. Enriched environment promotes behavioral and morphological recovery in a mouse model for the fragile $X$ syndrome. Proceedings of the National Academy of Sciences of the United States of America. 2005 Aug 09; 102(32): 11557-11562.

34. Martínez-Cerdeño V. Dendrite and spine modifications in autism and related neurodevelopmental disorders in patients and animal models. Developmental Neurobiology. 2017; 77(4): 393-404.

35. Gold WA, Krishnaraj R, Ellaway C, Christodoulou J. Rett syndrome: A genetic update and clinical review focusing on comorbidities. ACS chemical neuroscience. 2017 Nov 29.

36. Nomura Y. Early behavior characteristics and sleep disturbance in Rett syndrome. Brain \& development. 2005 Nov; 27 Suppl 1: S35-S42.

37. Chahrour M, Zoghbi HY. The story of Rett syndrome: from clinic to neurobiology. Neuron. 2007 Nov 08; 56(3): 422-437.

38. Lonetti G, Angelucci A, Morando L, Boggio EM, Giustetto M, Pizzorusso T. Early environmental enrichment moderates the behavioral and synaptic phenotype of MeCP2 null mice. Biological psychiatry. 2010 Apr 01; 67(7): 657665.

39. Kondo MA, Gray LJ, Pelka GJ, Leang S-K, Christodoulou J, Tam PPL, et al. Affective dysfunction in a mouse model of Rett syndrome: Therapeutic effects of environmental stimulation and physical activity. Developmental Neurobiology. 2016; 76(2): 209-224.

40. Kasarpalkar NJ, Kothari ST, Dave UP. BrainDerived Neurotrophic Factor in children with Autism Spectrum Disorder. Annals of Neurosciences. 2014; 21(4):129-133.

41. Oddi D, Crusio WE, D'Amato FR, Pietropaolo S. Monogenic mouse models of social dysfunction: 
implications for autism. Behav Brain Res. 2013 Aug 15; 251: 75-84.

42. Becker JAJ, Clesse D, Spiegelhalter C, Schwab Y, Le Merrer J, Kieffer BL. AutisticLike Syndrome in Mu Opioid Receptor Null Mice is Relieved by Facilitated mGluR4 Activity. Neuropsychopharmacology : official publication of the American College of Neuropsychopharmacology. 2014; 39(9): 20492060.

43. Klintwall L, Eikeseth S. Early and intensive behavioral intervention (EIBI) in autism. Comprehensive guide to autism: Springer; 2014. p. 117-37.

44. Garbugino L, Centofante E, D'Amato FR. Early Social Enrichment Improves Social Motivation and Skills in a Monogenic Mouse Model of Autism, the Oprm1 (-/-) Mouse. Neural plasticity. 2016; 2016: 5346161.

45. Potocki L, Bi W, Treadwell-Deering D, Carvalho CMB, Eifert A, Friedman EM, et al. Characterization of Potocki-Lupski Syndrome $(\mathrm{dup}(17)(\mathrm{p} 11.2 \mathrm{p} 11.2))$ and Delineation of a Dosage-Sensitive Critical Interval That Can Convey an Autism Phenotype. American Journal of Human Genetics. 2007; 80(4): 633-649.

46. Lacaria M, Spencer C, Gu W, Paylor R, Lupski JR. Enriched rearing improves behavioral responses of an animal model for CNV-based autistic-like traits. Human molecular genetics. 2012 Jul 15; 21(14): 3083-3096.

47. Hwang BJ, Mohamed MA, Brasic JR. Molecular imaging of autism spectrum disorder. International review of psychiatry (Abingdon, England). 2017 Dec; 12: 1-25.

48. Moy SS, Riddick NV, Nikolova VD, Teng BL, Agster KL, Nonneman RJ, et al. Repetitive behavior profile and supersensitivity to amphetamine in the C58/J mouse model of autism. Behav Brain Res. 2014 Feb 1; 259: 200214.

49. Teng BL, Nikolova VD, Riddick NV, Agster KL, Crowley JJ, Baker LK, et al. Reversal of social deficits by subchronic oxytocin in two autism mouse models. Neuropharmacology. 2016 Jun; 105: 61-71.

50. Teng BL, Nonneman RJ, Agster KL, Nikolova VD, Davis TT, Riddick NV, et al. Prosocial effects of oxytocin in two mouse models of autism spectrum disorders. Neuropharmacology. 2013 Sep; 72: 187-196.

51. Ryan BC, Young NB, Crawley JN, Bodfish JW, Moy SS. Social deficits, stereotypy and early emergence of repetitive behavior in the C58/ $\mathrm{J}$ inbred mouse strain. Behav Brain Res. 2010 Mar 17; 208(1): 178-188.

52. MuehImann AM, Edington G, Mihalik AC, Buchwald Z, Koppuzha D, Korah M, et al. Further characterization of repetitive behavior in C58 mice: Developmental trajectory and effects of environmental enrichment. Behavioural Brain Research. 2012 2012/12/01/; 235(2): 143-149.

53. Whitehouse CM, Curry-Pochy LS, Shafer R, Rudy J, Lewis $\mathrm{MH}$. Reversal learning in C58 mice: Modeling higher order repetitive behavior. Behavioural Brain Research. 2017 2017/08/14/; 332(Supplement C): 372-378.

54. Blanchard DC, Defensor EB, Meyza KZ, Pobbe $\mathrm{RLH}$, Pearson BL, Bolivar VJ, et al. BTBR T+tf/ J MICE: AUTISM-RELEVANT BEHAVIORS AND REDUCED FRACTONE-ASSOCIATED HEPARAN SULFATE. Neuroscience and biobehavioral reviews. 2012 07/01; 36(1): 285296.

55. Yang M, Perry K, Weber MD, Katz AM, Crawley JN. Social peers rescue autism-relevant sociability deficits in adolescent mice. Autism research : official journal of the International Society for Autism Research. 2011 Feb; 4(1): 17-27.

56. Reynolds S, Urruela M, Devine DP. Effects of environmental enrichment on repetitive behaviors in the BTBR $T+t f / J$ mouse model of autism. Autism research : official journal of the International Society for Autism Research. 2013 Oct; 6(5): 337-343.

57. Chomiak T, Turner N, Hu B. What We Have Learned about Autism Spectrum Disorder from Valproic Acid. Pathology research international. 2013; 2013: 712758.

58. Roullet FI, Lai JK, Foster JA. In utero exposure to valproic acid and autism--a current review of clinical and animal studies. Neurotoxicology and teratology. 2013 Mar-Apr; 36: 47-56.

59. Schneider T, Turczak J, Przewlocki R. Environmental enrichment reverses behavioral alterations in rats prenatally exposed to valproic acid: issues for a therapeutic approach in autism. Neuropsychopharmacology : official publication of the American College of Neuropsychopharmacology. 2006 Jan; 31(1): 36-46.

60. Yamaguchi H, Hara Y, Ago Y, Takano E, Hasebe $\mathrm{S}$, Nakazawa $\mathrm{T}$, et al. Environmental enrichment attenuates behavioral abnormalities in valproic acid-exposed autism model mice. Behav Brain 
Res. 2017 Aug 30; 333: 67-73.

61. Aronoff E, Hillyer R, Leon M. Environmental Enrichment Therapy for Autism: Outcomes with Increased Access. Neural plasticity. 2016; 2016: 2734915.

62. Marco EJ, Hinkley LB, Hill SS, Nagarajan SS. Sensory processing in autism: a review of neurophysiologic findings. Pediatric research. 2011 May; 69(5 Pt 2): 48R-54R.

63. Woo CC, Donnelly JH, Steinberg-Epstein $\mathrm{R}$, Leon M. Environmental enrichment as a therapy for autism: A clinical trial replication and extension. Behavioral neuroscience. 2015 Aug; 129(4): 412-422.

64. Woo CC, Leon M. Environmental enrichment as an effective treatment for autism: a randomized controlled trial. Behavioral neuroscience. 2013 Aug; 127(4): 487-497.

65. Weitlauf AS, Sathe N, McPheeters ML, Warren ZE. Interventions Targeting Sensory Challenges in Autism Spectrum Disorder: A Systematic Review. Pediatrics. 2017 Jun; 139(6). pii: e20170347. 